\title{
A ideia de um Tribunal Constitucional Internacional: da utopia à realidade
}

\author{
Maria Lucia de Paula Oliveira ${ }^{1}$
}

\begin{abstract}
Resumo: A proposta de um Tribunal Constitucional Internacional se constitui em iniciativa relevante no sentido da afirmação do princípio democrático e dos direitos humanos. A proposta guarda relação com a constitucionalização do direito internacional. Algumas possíveis críticas e dificuldades à criação são enfrentadas como a adoção da forma de um Tribunal, a competência da Corte quanto às eventuais inconstitucionalidades fáticas e a definição do rol de direitos que se constituirão nos critérios materiais para julgamento.

Palavras Chave: tribunal. constitucional, internacional. constitucionalização. competência.
\end{abstract}

Abstract: The proposal of an International Constitutional Court constitutes an important initiative in the purpose of the affirmation of the democratic principle and human rights. The proposal is related to the constitutionalizing of international law. Some possible criticism and difficulties are faced, such as the competence of the Court in confronting situations or facts that could be unconstitutional and the definition of a list of rights that will be the material jurisdiction of the Court.

Keywords: constitutional. international. court. constitutionalizing. jurisdiction.

\section{Introdução}

A proposta para criação de um Tribunal Constitucional Internacional merece toda a atenção da sociedade mundial. Trata-se de iniciativa relevante no sentido de buscar uma solução jurídica (e judicial) para a necessidade de afirmação democrática em face de legislação interna dos Estados que violarem seriamente os princípios do direito internacional relacionados à sua afirmação (salientando-se aqui a correlação estreita entre democracia e direitos humanos, especialmente a liberdade de informação jornalística, a liberdade de associação, e a liberdade de expressão). Tais liberdades são relevantes para o processo político e eleitoral, que deve assegurar a não discriminação entre candidatos, $o$ respeito às candidaturas e, evidentemente, a não ocorrência de fraude eleitoral, dentre outros direitos políticos essenciais à democracia. A proposta de criação foi acolhida pela União Africana, após sua proposição pela República da Tunísia, em 2013. As cortes internacionais hoje existentes não dão conta do papel que se pretende venha a desempenhar o Tribunal Constitucional Internacional. Isso porque o Tribunal Internacional de Justiça de Haia supõe, para sua atuação, que os dois Estados envolvidos concordem com a submissão ao Tribunal. Já o Tribunal Penal Internacional tem como competência julgar crimes internacionais, estando, ainda, limitado pela circunstância de que alguns dos países mais poderosos do mundo não terem aderido ao seu Estatuto (CHEMILLIER-GENDREAU,2015).

$\mathrm{O}$ projeto se mostra hoje uma ideia interessante, ainda que se possa, sem grandes dificuldades, visualizar as dificuldades no contexto político internacional atual para sua efetivação. Tais dificuldades, porém, não devem desanimar Aqueles comprometidos com uma visão cosmopolita dos direitos humanos. Ele deve ser encarado como uma "utopia realista", como proposto por Paulo Ferreira da Cunha

\footnotetext{
${ }^{1}$ Professora da Pontifícia Universidade Católica do Rio de Janeiro. Doutora em Direito - PUC-SP. Procuradora da Fazenda Nacional.
} 
(CUNHA, 2015). Uma "utopia realista", expressão também usada por John Rawls para referir seu projeto teórico para uma Sociedade dos Povos razoavelmente justa, se poria quando a teoria expande "...os limites da possibilidade política praticável e, ao fazê-lo, nos reconcilia com a nossa condição política e social.” (RAWLS, 2001). Aqui a utopia tem um papel importante "....arrancar, com um sopro renovador de metanóia, o conhecimento do político do seu presente marasmo, ou desencanto.”(CUNHA,1996). O desânimo ou descrédito no plano do direito internacional para uma solução que permita uma radicalização do constitucionalismo político no âmbito global é questionado, de forma marcante, pela iniciativa do Tribunal Constitucional Internacional, fazendo renascer as energias utópicas, que sempre alimentaram as grandes transformações políticas que levaram a construção de um sistema político mais respeitoso da democracia e dos direitos humanos.

Desde o Projeto da Paz Perpétua de Immanuel Kant, que não circunstancialmente alimentou toda uma vertente de cosmopolitismo político no Sécs. XX e no Século corrente e o projeto de uma República Mundial, se cogita de um projeto para a constitucionalização nas relações políticas internacionais. Na verdade, para Kant, o projeto da República Mundial se traduziria numa federação dos Estados livres, seguindo um direito das gentes concertado em comum, estabelecendo-se uma constituição republicana, sendo que essa constituição para Kant, funda-se na ideia de liberdade jurídica conjuga com o próprio resultado desejado, que seria a paz perpétua. Como se sabe, tal ideal parece ter parcialmente se materializado com a criação da ONU. Tal materialização está longe de esgotar o ideal de uma sociedade mundial democrática e livre.

A proposta de criação de um Tribunal Constitucional Internacional pode constituir, se implementada, um caminho importante para a afirmação em âmbito global de uma ordem constitucional internacional ainda em construção.

Gostaríamos, nas linhas seguintes, de apontar alguns aspectos relevantes quanto a alguns aspectos conceituais relevantes para a compreensão da relevância da iniciativa. Num primeiro momento, mostraremos a importância da constitucionalização do direito internacional. Numa visão mais tradicional da divisão dos saberes jurídicos, os planos do direito internacional e do direito constitucional eram excludentes. Hoje, no entanto, se fala sem grandes surpresas, em constitucionalismo global e internacional. De outra feita, há algumas diferentes concepções de como esse constitucionalismo deve se expressar do ponto de vista global. Defende-se aqui, nos moldes como inspirou a criação do próprio Tribunal Constitucional Internacional, um constitucionalismo pluralista.

Num segundo momento, enfrentaremos, em particular, a proposta de um caminho judicial, como a proposta de conciliação entre direitos humanos e princípio democrático (com atenção para o sistema de representação política, em especial o eleitoral), como formulada para a criação do Tribunal. Enfrentaremos, aqui, algumas dificuldades e críticas possíveis: a adoção da forma judicial, a dificuldade do enfrentamento da inconstitucionalidade fática ou circunstancial, e os limites mesmos dos direitos humanos que terão a proteção do Tribunal.

\section{Por um Constitucionalismo Internacional e Pluralista.}

Na linguagem jurídica, normalmente, se associa o termo "constituição" ao direito interno e não ao direito internacional. $O$ termo vem, desde o constitucionalismo moderno, associado a um conjunto de normas fundamentais pertinentes a organização dos poderes do Estado e a relação entre o Estado e os cidadãos. Mas nada impede (e aliás se assemelha recomendável) a transposição para o 
nível internacional das noções do constitucionalismo. Cuida-se aqui da transposição de noções como democracia, igualdade, separação dos poderes, rule of law e direitos fundamentais, dentre outras. Essa transposição se torna crucial em decorrência mesmo da assunção pela ordem internacional de um papel relevante na tomada de decisão pública, deixando essas decisões de estarem centradas exclusivamente no Estadonação (DE WET, 2006).

A ordem jurídica internacional vem sendo desenvolvida através do tempo, tendo como marco importante a adoção da Carta das Nações Unidas; não se assemelha correto, porém, denominá-la como constituição, já que ela vincula os Estadosmembros e não, propriamente, a comunidade internacional como um todo. Ademais, a comunidade internacional é hoje antevista como um conceito mais amplo que abrange organismos regionais (União Europeia ou União Africana, por exemplo), setoriais (OMC, dentre outros).

A constitucionalização da ordem internacional se traduz numa ampliação dos atores da comunidade internacional e num reforço da dimensão ética da juridicidade internacional, nos moldes do já ocorrido no âmbito do direito interno (noções como a de democracia e de direitos fundamentais se tornaram referenciais para uma releitura do direito a partir de uma perspectiva da moralidade política). Assim, existiriam normas jus cogens e obrigações erga omnes: o que está em jogo é a concepção de que determinadas obrigações são universais e, mais do que isso, universalmente obrigatórias. E a existência de um jus cogens não é uma petição de princípio ou um ideal; resulta do esforço teórico e prático para concretização dos direitos humanos. Cuida-se de ir além das cláusulas gerais que os afirmam e encontrar pontos de convergência que permitiram a formulação de um sistema de direito objetivo que possa ser, de forma democrática, aceita por todos os envolvidos. Nesse propósito, é indispensável o reforço do sistema político e jurídico que subjaz à ordem constitucional internacional. Daí a importância de iniciativas como a ora em foco, para criação de um Tribunal Constitucional Internacional. Um constitucionalismo internacional ou global, a ser buscado por meio de novas iniciativas políticas, é fundamental para prevenir o processo de descontrolada desformalização do direito internacional, com prejuízo da estabilidade legal e da própria legitimidade das decisões jurídicas, como lembrado por Jürgen Habermas.

O processo de constitucionalização global não é linear, mas uma constante emergência e deliberada criação de elementos constitucionais na ordem internacional (PETERS,2009). Uma das consequências desse processo é uma nova perspectiva da própria noção da soberania estatal. Numa perspectiva constitucionalista, a noção deve ser revista, mas não especialmente abandonada. A emergência de um constitucionalismo global não coloca em xeque, ao contrário do que se poderia imaginar de um ponto de vista mais informado pela teoria de Hans Kelsen, a soberania do Estados, que continuam instância importantes de construção desse mesmo constitucionalismo global. Certamente, o princípio da subsidiariedade é importante, bem como o princípio de uma igualdade soberana dos Estados, pois eles permitem respeitar o pluralismo da ordem constitucional internacional. Nesse sentido, parece andar bem o projeto do Tribunal Constitucional Internacional ao estabelecer a necessidade, sempre que possível, do esgotamento das instâncias judiciais do direito doméstico dos Estados, antes de se buscar a tutela do Tribunal.

Revela-se bastante interessante a perspectiva de um pluralismo constitucional no plano internacional (COHEN, 2012). Esse pluralismo constitucional se traduz numa solução não monista (Não se defende a criação de um Estado mundial, como a propugnada por Otfried Höffe (OLIVEIRA, 2013)). A complexidade da ordem jurídica internacional e a própria afirmação dos Estados como instâncias importantes 
de afirmação do próprio direito internacional permite afirmar um caminho alternativo, mas que não reduz às instituições políticas internacionais a meros espectros do poder político prevalente, apostando no poder das instituições jurídicas de buscar uma justiça global. Por outro lado, não se busca construir generalizações artificiais, fora dos contextos políticos específicos. Mas, com exercício de prudência política, construir caminhos de institucionalização jurídica comprometidos com a explicitação de situações de marginalização, opressão e de sofrimento decorrentes de uma ordem jurídica pouco ou nada compromissada com a democracia e com os direitos humanos. A estruturação do Tribunal Constitucional Internacional deve estar necessariamente comprometida com tal propósito, evitando se tornar mais uma instância no plano internacional, de imposição de mera vontade política hegemônica.

\section{Sobre o Tribunal Constitucional Internacional: desafios para sua criação}

Não existe no plano do direito internacional hoje um órgão jurídico que esteja apto a exercer o papel que se pretende atribuir ao Tribunal Constitucional Internacional. Um dos questionamentos que se coloca, porém, concerne à própria adoção de uma solução jurisdicional. Com efeito, se questiona se a forma do Tribunal seria a mais conveniente, considerando o déficit democrático do controle judicial. Coloca-se, ainda, as dificuldades inerentes ao controle judicial para dar conta das situações de "constitucionalização simbólica" e de "constitucionalização abusiva".

O primeiro questionamento concerne a uma mitigação da solução política e de deliberação pública, com a introdução de um Tribunal que transformará o problema em questão constitucional. Tal questionamento, porém, parece supor que as questões constitucionais não são também políticas, o que não é verdade. Ademais, a constitucionalização do direito, se trouxer junto a sua judicialização, estará longe, ao menos no plano global e nas circunstâncias da atualidade, a um governo mundial pelos juízes. O problema, além disso, não seria a constitucionalização do direito internacional, por meio do controle judicial, mas a sua democratização, que deve ser buscada da forma mais eficiente possível.

Um segundo ponto objeto de questionamento concerne aos parâmetros mesmo a serem adotados pelo Tribunal Constitucional Internacional, ou seja, que direito mesmo seria aplicado por esse Tribunal. A ver de alguns críticos, não haveria ainda um corpo de direito desenvolvido apto a ser aplicado em um eventual controle judicial na matéria de competência da referida Corte; a definição mesmo do que seriam instituições e eleições democráticas, e as peculiaridades locais e regionais, traria uma dificuldade grande para a atuação do Tribunal (LANDAU,2013). Ora, sem dúvida, esse é um desafio para o estabelecimento do Tribunal: definir um corpo de standards jurídicos necessariamente gerais, mas suficientes, que funcionem como parâmetros para a previsibilidade e segurança jurídicas, indispensáveis para a legitimação do próprio Tribunal. Logo, tal crítica, a nosso ver, não é necessariamente um empecilho, mas um desafio na criação do mesmo.

Um questionamento concerne à possibilidade de controle judicial não só das situações de "constitucionalização simbólica" (em que o Texto Constitucional dos Estados se constitui em "letra morta" do ponto de vista da integralidade do sistema infraconstitucional), mas de atos de "constitucionalismo abusivo", que sob o manto de uma constitucionalidade formal, tem a consequência do retrocesso democrático. Por mais que, infelizmente, esse seja um quadro bastante identificável nos dias de hoje, há algumas dificuldades no exercício de uma jurisdição constitucional internacional, especialmente nesses últimos casos, já que a aparência de preservação da democracia gera dificuldades no exame da situação. 
Coloca-se de imediato qual seria a competência do Tribunal, se ele também apreciaria a inconstitucionalidade circunstancial e a fática, ou seja, aquelas situações em que a inconstitucionalidade do ato normativo decorre das circunstâncias de fato, que fazem surgir muitas vezes um "estado de coisas inconstitucional". Existem dificuldades nesse caso, pois caberia ao Tribunal a apreciação de uma série de elementos conectados com a realidade local e regional, da mais ampla natureza. No âmbito doméstico, em alguns Estados, se admite a submissão à Corte Constitucional de tal espécie de ferimento à Constituição. Seria possível imaginar que o Tribunal Constitucional Internacional também pudesse fazer isso, inclusive com relação a emendas constitucionais postas conforme à Constituição, mas que acabam na prática por restringir a democracia? As dificuldades concernem aos elementos a serem apreciados pelo Tribunal. Para alguns, tal tipo de atuação seria mais político do que jurídico e de difícil apreciação, especialmente numa instância supranacional.

Dentro do propósito de realização do que hoje é ainda um projeto, parece-nos que não convém excluir o controle de constitucionalidade de todos os atos normativos de direito interno, mesmo que tal inconstitucionalidade, para sua identificação, suponha a apreciação - como aliás deve sempre ocorrer- dos contextos de aplicação do direito. Logo, poder-se-ia admitir a inconstitucionalidade circunstancial, ou seja, a situação em que a inconstitucionalidade resulta de atos normativos, que a partir dos contextos para sua aplicação, se perceberiam como inconstitucionais, exigindo-se o esgotamento das vias de direito doméstico. Parece-nos que a inconstitucionalidade circunstancial não pode estar fora da apreciação da Corte. Outra, porém, seria a situação da inconstitucionalidade fática: caberia ao Tribunal apreciar fatos, acontecimentos ocorridos e que não tem um substrato normativo, simplesmente por que tais condutas, ainda que do Poder Público, redundaram em práticas que ferem os direitos humanos e o princípio democrático? Aqui talvez coubesse uma postura restritiva, já que nesses casos a decisão judicial não teria o condão de prevenir ou reprimir a inconstitucionalidade. Nesse caso teríamos, claramente, um julgamento muito mais político que jurídico, já que não se trata de evitar que um ato normativo continue a produzir efeitos.

Por fim, é bastante interessante a conjugação que estaria sob a tutela do Tribunal Constitucional Internacional. Com efeito, o que se coloca como dificuldade na implantação de instituições políticas internacionais é sempre o déficit democrático, inclusive do ponto de vista do Direito interno dos Estados. Mas um dos papéis do Tribunal é justamente buscar que as Constituições hoje já compromissadas com os direitos humanos e com o princípio democrático, não sofram regressões em seu processo político, algumas decorrentes mesmo das arbitrariedades da política internacional. Nesse sentido, parece-nos feliz o delinear da competência material do Tribunal Constitucional Internacional. Talvez fosse interessante para trilhar nesse pormenor o estabelecimento de uma nova Carta de Direitos Humanos Fundamentais, que conjugasse a proteção dos direitos humanos com diretrizes de homenagem ao princípio democrático que devem nortear o exercício da soberania dos Estados, disciplinando esses direitos na perspectiva da organização política dos Estados (FERRARA, 2012). É relevante a percepção clara da dimensão política dos direitos humanos, tão bem lembrada por Hannah Arendt por meio da famosa referência ao "direito de ter direitos" (BENHABIB, 2011).

\section{Considerações Finais}

É indispensável no sistema jurídico-político internacional uma instância ( e se mostra interessante que ela seja um tribunal), que de forma inclusiva, seja 
instrumento de sedimentação do princípio democrático, em sua conjugação com os direitos humanos. Não existe hoje nenhuma instância no plano internacional que exerça esse papel (seja a Corte de Haia, seja o Tribunal Penal Internacional não ocupam esse papel). Ademais, quando se coloca a questão da definição dos próprios direitos humanos, com atenção aos contextos de aplicação, do ponto de vista mundial, talvez os standards construídos a partir da prática judicial possam trazer uma contribuição importante. Por tais razões, a mencionada Proposta se nos assemelha a um "sopro de utopia" na política mundial que não pode, e não deve, se esvanecer.

\section{Referências Bibliográficas}

BENHABIB, S. Dignity in Adversity - Human Rights in Troubled Times. Cambridge: Polity Press, 2011.

CHEMILLIER-GENDREAU, M. Tribunal Constitucional Internacional - Para Obrigar os Estados a Cumprir sua Palavra”. Le Monde Diplomatique Brasil .http://www.diplomatique.org.br/print.php?tipo=ar\&id $=1514$.

COHEN, J. Globalization and Sovereignty - Rethinking Legality, Legitimacy and Constitucionalism. Cambridge: Cambridge University Press, 2012.

CUNHA,P.F. Constituição, Direito e Utopia - Do Jurídico-Constitucional nas Utopias Políticas. Coimbra: Coimbra Editora, 1996.

CUNHA, P.F. La Cour Constitutionelle International (ICCo) - Une Idée qui fait son chemin. Notandum, no. 38, mai-ago 2015, CEMOrOC-Feusp/IJI-Univ. do Porto.

DE WET, E. "The International Constitucional Order". International and Comparative Law Quarterly. Vol.55, Janeiro 2006, pp.51-76.

FERRARA, A. "The Idea of a Charter of Fundamental Human Rigths", CORRADETTI, C. (editor). Philosophical Dimensions of Human Rights. New York: Springer, 2012.

LANDAU, D. Abusive Constitutionalism (April 3, 2013). UC Davis Law Review, Fall 2013, Forthcoming; FSU College of Law, Public Law Research Paper No. 646. Available at SSRN: http://ssrn.com/abstract=2244629

NEVES, M. Transconstitucionalismo. São Paulo: Martins Fontes,2009.

OLIVEIRA, M.L.P. “A Caminho de uma República Mundial Democrática? Otfried Höffe e as Instituições Políticas Internacionais", in GUEDES, M.A. Teoria do Estado e do Direito no Século XXI: Novos Diálogos Brasil-Argentina. Rio de Janeiro: All Print, 2013.

PETERS, A. "The Merits of Global Constitutionalism", Indiana Journal of Global Legal Studies. Vol.16: Iss.2, Article 2.

RAWLS, J. O Direito dos Povos. Tradução de Luís Carlos Borges. São Paulo: Martins Fontes, 2001. 